\title{
Hemodynamic Responses to Two Different Anesthesia Regimens in Compromised Left Ventricular Function Patients Undergoing Coronary Artery Bypass Graft Surgery:Etomidate-Midazolam Versus Propofol-Ketamine
}

\author{
Nahid Aghdaii ${ }^{1}$; Mohsen Ziyaeifard ${ }^{1,3}$; Seyedeh Zahra Faritus ${ }^{1}$; Rasoul Azarfarin ${ }^{1}$ \\ ${ }^{1}$ Rajaie Cardiovascular Medical Research Center, Iran University of Medical Sciences, Tehran, Iran \\ *Corresponding author: Mohsen Ziyaeifard, Rajaie Cardiovascular Medical Research Center, Iran University of Medical Sciences, Tehran, Iran. Tel: +98-2123922152, Fax:+98-2122663293, \\ E-mail:Mziyaeifard@yahoo.com
}

Received: February 14, 2015; Revised: March 1, 2015; Accepted: March 8, 2015

\begin{abstract}
Background: Various methods have been suggested to prevent hemodynamic instability caused by propofol and adverse effects caused by etomidate induction. The current study evaluated hemodynamic effects of propofol-ketamine mixture in comparison to etomidatemidazolam mixture during anesthesia induction.

Objectives: The aim of this study was to evaluate the hemodynamic effects of etomidate-midazolam by comparing it with propofolketamine for the induction of anesthesia in patients with left ventricular dysfunction undergoing coronary artery bypass graft surgery. Patients and Methods: One-hundred patients aged between 40 and 65 with coronary artery disease and low ejection fraction scheduled for elective coronary artery bypass surgery participated in this study. The patients were randomly allotted to one of the two groups to receive either propofol-ketamine or etomidate-midazolam combination. Two groups were compared for pain on injection and myoclonus, Heart Rate(HR), Systolic Blood Pressure(SBP), Diastolic Blood Pressure(DBP), Mean Arterial Pressure (MAP), Cardiac Index (CI) and Systemic Vascular Resistance (SVR), before and one minute after induction of anesthesia, and one, three and five minutes after intubation.

Results: Incidence of pain on injection (2 - 4\%) and myoclonus (10\%) was less in both groups. The hemodynamic response was similar in the two groups for all variables over the time interval, except for $\mathrm{CI}$ at one and three minutes after intubation $(\mathrm{P}=0.024$ and $\mathrm{P}=0.048$, respectively), and SVR in five minutes after intubation $(\mathrm{P}=0.009)$, with differences being statistically significant.

Conclusions: Both anesthetic regimens were acceptable for induction in patients with coronary artery disease and left ventricular dysfunction undergoing coronary artery bypass graft surgery.
\end{abstract}

Keywords: Left Ventricular Dysfunction; Coronary Artery Bypass; Combined-Anesthetics; Hemodynamics

\section{Background}

Induction of anesthesia is a critical period in cardiac patients. Anesthetic induction techniques for cardiovascular surgery are usually based on considerations such as hemodynamic stability, maintenance of the balance between myocardial oxygen demand and supply and minimal intubation stress response $(1,2)$, that may cause an increased risk of morbidity and mortality in patients with cardiovascular or cerebral disease (3). Among the cardiac surgical cases, patients with Coronary Artery Disease (CAD) and low Ejection Fraction (EF) that are required to undergo Coronary Artery Bypass Grafting (CABG) surgery are a high-risk group. There are several literature reports regarding induction of anesthesia with agents such as thiopentone, propofol, etomidate, midazolam and ketamine (4-10). The search for the ideal balanced intravenous general anesthetic over the past few decades has led many investigators to look into anesthetic drug combinations. Of the many anesthetic combinations that have been investigated, the propofolketamine combination has been a popular choice because of the specific properties intrinsic in each drug. Propofol is a sedative-hypnotic intravenous anesthetic that has a known cardiodepressant effect that produces hypotension, $(11,12)$ whereas ketamine is a dissociative intravenous anesthetic that has known cardiostimulant properties. The combination of propofol and ketamine has been studied in outpatients and in patients undergoing minor non-cardiac surgery, by numerous authors (13-17). In most of these studies the addition of low-dose ketamine has been shown to attenuate the cardiovascular depressing effects of propofol. However, we did not find any investigation about the use of Propofol-Ketamine (PK) combination in low EF patients undergoing $C A B G$ surgery. On the other hand, etomidate is the most appropriate drug in patients with compromised cardiopulmonary function because of its minimal cardiovascular and respiratory depressant effects, (18) however, etomidate has some side effects such as injection pain, adrenal suppression and myoclonus. Pretreatment with low dose of a hypnotic agent such as midazolam (19-21), reduces myoclonus. The incidence of myoclonus due to etomidate depends on the dosage and speed of injection (22). It seems

Copyright (C2015, Iranian Society of Regional Anesthesia and Pain Medicine(ISRAPM). This is an open-access article distributed under the terms of the Creative Commons Attribution-NonCommercial 4.0 International License (http://creativecommons.org/licenses/by-nc/4.0/) which permits copy and redistribute the material just in noncommercial usages, provided the original work is properly cited. 
that induction of anesthesia with combination of drugs such as Propofol with Ketamine (PK) and Etomidate with Midazolam (EM) will eliminate or at least reduce these complications. The current study was performed as to the best of our knowledge there are no previous investigations comparing PK and EM combination in low EF patients undergoing CABG.

\section{Objectives}

The aim of this study was to evaluate hemodynamic responses to two different anesthesia regimens including etomidate-midazolam and propofol-ketamine in compromised ventricular function patients undergoing coronary artery bypass graft surgery.

\section{Patients and Methods}

In this prospective, randomized study the participants included one hundred patients (68 males and 32 females; age range: 40 - 65 years old) of American Society of Anesthesiologists (ASA) class II and III with coronary artery disease and left ventricular dysfunction (ejection fraction $<45 \%$ ) scheduled for elective coronary artery bypass surgery at Rajaie Cardiovascular Medical and Research Center. The study protocol was approved by the Division Ethics Committee of our institute as a prospective, randomized clinical study. The patients' records regarding age, gender, weight, ejection fraction, time required for laryngoscopy and intubation were stored in our database. Patients with congenital or valvular disease, suppressed immune function, known adrenal insufficiency, chronic inflammatory diseases, history of early steroid use (about six months), allergy to the study drugs, history of stroke, convulsion, seizure, or other neurologic diseases, patients with opium addiction, severe hepatic and renal insufficiency, prolonged laryngoscopy or difficult intubation, severe systemic noncardiac disease, as well as those who were undergoing a reoperation or combined cardiac valve surgery with CABG, were excluded. All patients continued their medications up to the day of surgery and were premedicated with intramuscular morphine at $0.1 \mathrm{mg} / \mathrm{kg}$ and lorazepam $1 \mathrm{mg}$ one hour before entering the operation room. Basic hemodynamic monitoring, consisting of a five-lead electrocardiogram, pulse oximetry and invasive arterial blood pressure, and specific hemodynamic monitoring, consisting of cardiac index and systemic vascular resistance by use of Non-Invasive Cardiac Output system (NICO; NOVAMETRIX, made in America) were initiated before the induction of anesthesia. A large bore intravenous catheter, (G16 or G14) at forearm (if possible), for reduction or prevention of pain on propofol or etomidate injection, and arterial line catheter were inserted after local anesthetic infiltration of the insertion site. During the induction, any pain on injection and any involuntary movements were noted.

\subsection{Intervention}

The patients were randomly divided to two groups of 50 each, by computer generated random numbers. Group PK $(n=50)$ received admixture of propofol $1 \mathrm{mg} / \mathrm{kg}$ and ketamine $1 \mathrm{mg} / \mathrm{kg}$ in one syringe intravenously over 30 60 seconds and Group EM $(\mathrm{n}=50)$ received $0.06 \mathrm{mg} / \mathrm{kg}$ midazolam into a freely running infusion of saline solution over 90 seconds before and during injection of 0.2 $\mathrm{mg} / \mathrm{kg}$ etomidate intravenously for induction. Analgesia was obtained with sufentanil $2.5 \mu \mathrm{g} / \mathrm{kg}$. For prevention or at least reduction of pain on injection in both groups, sufentanil was injected before anesthetic drugs. Intravenous injection of cisatracurium $0.2 \mathrm{mg} / \mathrm{kg}$ was performed to facilitate endotracheal intubation with an appropriate-sized endotracheal tube; this was done 90 seconds after the injection. Time period until loss of eyelash reflex was taken as the induction time. After checking and securing the endotracheal tube, and insertion of central venous line, mechanical ventilation was instituted to maintain eucapnia. Anesthesia was maintained with continuous infusion of midazolam, sufentanil and atracurium in both groups. Our program for treatment of any hemodynamic instability, including hypertension (MAP > 20\% from baseline), was starting of intravenous nitroglycerine infusion and for treatment of hypotension (reduction in Systolic Blood Pressure to less than $90 \mathrm{mmHg}$ ) was placing of patient in the trendelenburg position (up to $30^{\circ}$ angle), and infusion of lactated Ringer's solution ( $5-7 \mathrm{mg} / \mathrm{kg}$ ) and if these interventions were insufficient, injection of ephedrine. If bradycardia occurred $(\mathrm{HR}<40), 0.5 \mathrm{mg}$ of atropine was injected. Hemodynamic parameters, including Heart Rate (HR), Systolic Blood Pressure (SBP), Diastolic Blood Pressure (DBP), Mean Arterial blood Pressure (MAP) and Cardiac Index (CI), were measured and recorded before induction of anesthesia as a baseline (T0), one minute after induction (T1), one minute after intubation (T2), and three and five minutes after intubation (T3 and T4), and Systemic Vascular Resistance (SVR) was measured before induction of anesthesia as a baseline (TO), one minute after induction (T1) and five minutes after intubation (T4). Basic hemodynamic monitoring (HR, SBP, MAP, DBP) was done for all patients and specific hemodynamic monitoring including Cardiac Index (CI) and Systemic Vascular Resistance (SVR) was done for 17 patients from each groups. The observer who recorded all measurements was blinded to the induction agents.

\subsection{Statistical Analysis}

The collected data were entered into the SPSS software for windows v. 21.0 (SPSS Inc., Chicago, IL, USA). The categorical parameters in the two study groups were analyzed by using Chi-square test or Fisher's exact test as appropriate. Differences among the hemodynamic variables recorded over time in each study group (within group) were analyzed using the repeated measures Analysis of Variance (ANOVA). Differences in mean values of hemodynamic parameters were analyzed using Student's t test. The hypothesis of this study was that there would be a clinically meaningful difference in hemodynamic responses to the two different anesthetic regimens. Quantitative data were 
expressed as Mean \pm Standard Deviation(SD).APvalue of $\leq$ 0.05 was considered statistically significant.

\section{Results}

In the present study, the patients' characteristics including gender, age, weight, ASA class, ejection fraction and time required for intubation distribution in the two groups were found to be statistically similar $(\mathrm{P}>0.05)$ (Table 1). All patients had moderate left ventricular dysfunc- tion with ejection fraction ranging between $30 \%$ and $45 \%$. During the induction, pain on injection occurred in two (4\%) patients of Group EM and in one (2\%) patient of Group PK yet the difference was not statistically significant $(\mathrm{P}=$ $1.000)$. Five (10\%) patients had involuntary movements after receiving the etomidate injection as compared to propofol injection $(0 \%)(\mathrm{P}=0.056)$. The heart rate and arterial blood pressure (systole, mean and diastole) measured at various time intervals were comparable between the two groups $(\mathrm{P}>0.05)$ as shown in Table 2 (Figure 1$)$.

Table 1. Patient Characteristics in the Etomidate-Midazolam Group and Propofol-Ketamine Group a,b

\begin{tabular}{|c|c|c|c|}
\hline Patient Characteristics & EM Group $^{\mathrm{c}}$ & PK Group $^{\mathrm{C}}$ & P Value \\
\hline Gender (F/M), n (\%) & $17 / 33(34 / 66)$ & $15 / 35(30 / 70)$ & 0.668 \\
\hline Age, $y$ & $57.16 \pm 5.6$ & $57.36 \pm 5.5$ & 0.858 \\
\hline ASA class, $\mathbf{n}(\%)$ & & & 0.534 \\
\hline II & $33(66)$ & $30(60)$ & \\
\hline III & $17(34)$ & $20(40)$ & \\
\hline $\mathbf{E F}, \%$ & $35.8 \pm 4.6$ & $35.3 \pm 4.8$ & 0.602 \\
\hline Weight, kg & $71.28 \pm 11.2$ & $72.06 \pm 8.7$ & 0.700 \\
\hline Time required for intubation, $s$ & $22.50 \pm 4.3$ & $23.40 \pm 5.6$ & 0.370 \\
\hline
\end{tabular}

Table 2. Basic Hemodynamic Parameters at Various Time Intervals in the Etomidate-Midazolam and Propofol-Ketamine Group a,b

\begin{tabular}{|c|c|c|c|}
\hline Parameters & EM Group ${ }^{\mathrm{C}}$ & PK Group $^{\text {C }}$ & P Value \\
\hline \multicolumn{4}{|l|}{ Heart Rate, beat/min } \\
\hline Baseline (HR-T0) & $73.9 \pm 12.5$ & $72.8 \pm 11.4$ & 0.647 \\
\hline 1 min after induction (HR-T1) & $64.0 \pm 10.9$ & $63.0 \pm 10.0$ & 0.615 \\
\hline $1 \mathrm{~min}$ after intubation (HR-T2) & $83.9 \pm 11.1$ & $83.0 \pm 10.4$ & 0.665 \\
\hline 3 min after intubation (HR-T3) & $75.3 \pm 10.9$ & $75.10 \pm 10$ & 0.897 \\
\hline 5 min after intubation (HR-T4) & $71.0 \pm 11.0$ & $71.0 \pm 9.0$ & 0.937 \\
\hline \multicolumn{4}{|l|}{ Systolic arterial BP, mmHg } \\
\hline Baseline (SBP-TO) & $147.6 \pm 7.0$ & $148.4 \pm 7.5$ & 0.557 \\
\hline 1 min after induction (SBP-T1) & $110.3 \pm 6.4$ & $111.1 \pm 7.0$ & 0.581 \\
\hline $1 \mathrm{~min}$ after intubation (SBP-T2) & $143.8 \pm 7.4$ & $146.0 \pm 7.3$ & 0.133 \\
\hline 3 min after intubation (SBP-T3) & $131.0 \pm 6.4$ & $131.0 \pm 6.8$ & 0.952 \\
\hline 5 min after intubation (SBP-T4) & $128 \pm 6.8$ & $129.6 \pm 7.1$ & 0.245 \\
\hline \multicolumn{4}{|l|}{ Mean arterial $\mathrm{BP}, \mathrm{mmHg}$} \\
\hline Baseline (MAP-T0) & $100.5 \pm 7.0$ & $100.5 \pm 6.0$ & 1 \\
\hline 1 min after induction (MAP-T1) & $82.4 \pm 6.5$ & $82.0 \pm 6.3$ & 0.734 \\
\hline 1 min after intubation (MAP-T2) & $99.2 \pm 8.4$ & $99.6 \pm 9.3$ & 0.857 \\
\hline 3 min after intubation (MAP-T3) & $88.7 \pm 9.7$ & $89.4 \pm 9.1$ & 0.711 \\
\hline 5 min after intubation (MAP-T4) & $95.9 \pm 6.4$ & $95.9 \pm 8.2$ & 0.968 \\
\hline \multicolumn{4}{|l|}{ Diastolic arterial BP, mmHg } \\
\hline Baseline (DBP-TO) & $77.1 \pm 8.8$ & $77.0 \pm 7.1$ & 0.96 \\
\hline $1 \mathrm{~min}$ after induction (DAP-T1) & $68.6 \pm 7.7$ & $68.7 \pm 6.7$ & 0.956 \\
\hline 1 min after intubation (DAP-T2) & $73.6 \pm 9.7$ & $74.2 \pm 8.9$ & 0.739 \\
\hline 3 min after intubation (DAP-T3) & $72.3 \pm 7.5$ & $72.7 \pm 6.5$ & 0.777 \\
\hline 5 min after intubation (DAP-T4) & $78.9 \pm 6.0$ & $78.3 \pm 7.8$ & 0.666 \\
\hline
\end{tabular}


Figure 1. Hemodynamic Parameters at Various Time Intervals in the Etomidate-Midazolam and Propofol-Ketamine Group

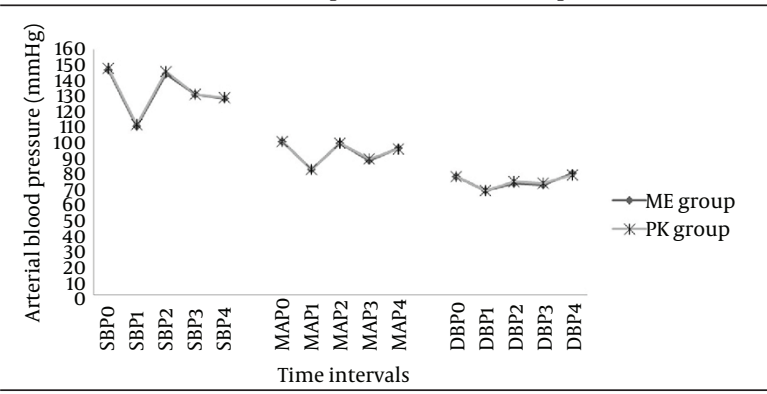

Abbreviations: DBP, diastolic blood pressure; Group EM, Etomidate-Midazolam group; Group PK, Propofol-Ketamine group; SBP, systolic blood pressure; T0, before induction of anesthesia (baseline); T1, one minute after induction; T2, 1 minutes after intubation; T3, three minutes after intubation; and T4, five minutes after intubation.

Table 3. Specific Hemodynamic Parameters at Various Time Intervals in the Etomidate-Midazolam and Propofol-Ketamine Group a,b

\begin{tabular}{|c|c|c|c|}
\hline Parameters & EM Group $^{\mathrm{C}}$ & PK Group $^{\mathrm{C}}$ & PValue \\
\hline \multicolumn{4}{|l|}{ Cardiac Index, $\mathrm{L} / \mathrm{min} / \mathrm{m}^{2}$} \\
\hline Baseline (CI-T0) & $2.68 \pm 0.3$ & $2.82 \pm 0.2$ & 0.099 \\
\hline $1 \mathrm{~min}$ after induction (CI-T1) & $2.17 \pm 0.3$ & $2.31 \pm 0.2$ & 0.068 \\
\hline $1 \mathrm{~min}$ after intubation (CI-T2) & $2.69 \pm 0.3$ & $2.88 \pm 0.2$ & $0.024^{\mathrm{d}}$ \\
\hline 3 min after intubation (CI-T3) & $2.48 \pm 0.3$ & $2.65 \pm 0.2$ & $0.048^{\mathrm{d}}$ \\
\hline 5 min after intubation (CI-T4) & $2.38 \pm 0.3$ & $2.53 \pm 0.2$ & 0.068 \\
\hline \multicolumn{4}{|l|}{$\begin{array}{l}\text { Systemic vascular resistance, } \\
\text { dynes } / \mathrm{cm}^{5}\end{array}$} \\
\hline Baseline (SVR-To) & $1837.67 \pm 208.6$ & $1852.4 \pm 179.3$ & 0.824 \\
\hline $1 \mathrm{~min}$ after induction (SVR-T1) & $1342.3 \pm 163.5$ & $1298.1 \pm 118.1$ & 0.366 \\
\hline 5 min after intubation (SVR-T4) & $1249.1 \pm 160.1$ & $1116.4 \pm 120.6$ & $0.009^{\mathrm{d}}$ \\
\hline \multicolumn{4}{|c|}{$\begin{array}{l}\text { abbreviations: CI, cardiac index; Group EM, Etomidate-Midazolam } \\
\text { group; Group PK, Propofol-Ketamine group; SVR, systemic vascular } \\
\text { resistance; min, minutes; T0, before induction of anesthesia (baseline); } \\
\text { T1, one minute after induction; T2, one minute after intubation; T3, } \\
\text { three minutes after intubation; and T4, five minutes after intubation. } \\
\text { b Values are presented as Mean } \pm \text { SD. } \\
\text { c } n=17 \text {. } \\
\text { d Statistical significance of parameters. }\end{array}$} \\
\hline
\end{tabular}

Changes in HR, SBP, MAP and DBP were not statistically significant at different time intervals between the two groups. There was a significant decrease from the baseline in heart rate $(\mathrm{P}=0.001$ in each group $)$, systolic, diastolic and mean arterial pressure $(\mathrm{P}=0.001$ in each group), after induction in the two groups. All of these variables increased near baseline one minute after intubation, while heart rate increased above baseline one minute after intubation. However, intergroup comparison revealed no changes in these variables during this period (Table 2, Figure 1). We were able to measure CI and SVR in 17 patients from each group. There was a significant decrease in $\mathrm{CI}$ from baseline $(\mathrm{P}=0.001$ in each group) after induction and then a significant increase after intubation $(\mathrm{P}=0.001$ in each group) to above baseline, which was more prominent in the PK group (Table 3) (Figure 2). Increases in CI were significantly different at one and three minutes after intubation (T2, T3) between the two groups $(\mathrm{P}=0.024$ for $\mathrm{T} 2$ and $\mathrm{P}=0.048$ for T3). There was a significant decrease from baseline in SVR
Figure 2. Cardiac Index at Various Time Intervals in the Etomidate-Midazolam and Propofol-Ketamine Group

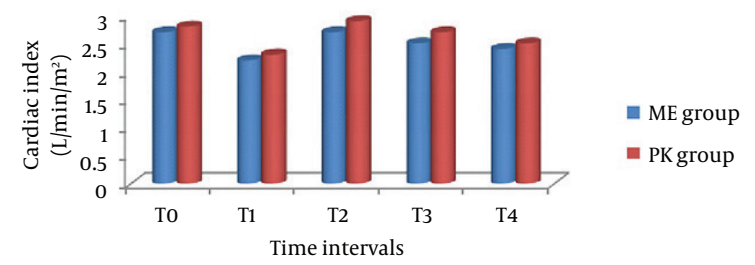

Abbreviations: CI, cardiac index; Group EM, etomidate-midazolam group; Group PK, Propofol-Ketamine group; To, before induction of anesthesia (baseline); T1, one minute after induction; T2, one minute after intubation; T3, three minutes after intubation; and T4, five minutes after intubation.

Figure 3. Systemic Vascular Resistance at Various Time Intervals in the Etomidate-Midazolam and Propofol-Ketamine Group

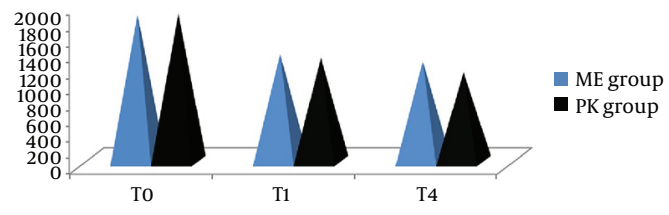

Abbreviations: Group EM, Etomidate-Midazolam group; Group PK, Propofol-Ketamine group; SVR, systemic vascular resistance; To, before induction of anesthesia (baseline); T1, one minute after induction; T2, one minute after intubation; T3, three minutes after intubation; and T4, five minutes after intubation.

at different time intervals in both groups $(\mathrm{P}=0.001$ in each group). Intragroup comparison revealed that there was no significant change in SVR during induction and one and three minutes after intubation, however there was a significant decrease in SVR five minutes after intubation $(\mathrm{P}=$ 0.009) (Table 3, Figure 3).

\section{Discussion}

There are no certain techniques or drugs in anesthetic methods to be used for compromised ventricular function patients undergoing coronary artery bypass graft surgery. There are some concerns about frequently used drugs and methods. The present study demonstrated that a combination of intravenous induction drugs (etomidate-midazolam versus propofol-ketamine) can be safely used for anesthetizing high-risk patients undergoing CABG. The use of etomidate and propofol has been considered preferable over other intravenous anesthetic agents in these groups of patients. However, etomidate has some side effects such as injection pain, adrenal suppression and myoclonus. The study of Pandey et al. (23) reported that etomidate provides more stable hemodynamic parameters presumably due to prevention of cortisol flow on induction by temporary suppression of cortisol synthesis, and concluded that maintenance of 
near-normal stress hormone levels under anesthesia is associated with better outcomes (11). Thus, we did not worry about adrenal suppression of etomidate in our patients. Induction of anesthesia with etomidate also results in dose-dependent myoclonus in $50-80 \%$ of patients without premedication (22). In our study, because of pretreatment with midazolam and reduced induction dose of etomidate, only $10 \%$ of patients had myoclonus. These results were similar to other studies that demonstrated incidence of myoclonus due to etomidate depends on the dosage and speed of injection and pretreatment with drugs such as midazolam, magnesium and ketamine (19-22). The findings of the present study showed that pain on injection was higher with the use of etomidate as compared to propofol ( $4 \%$ vs. $2 \%$ ). This result was in contrary with the results of studies done by Kosarek et al. (24), Ayuso et al. (25) and Nyman et al. (26). We believe that the main causes of pain on injection were site of injection (dorsum of hand), (27) size of catheter (gauge 18 or 20) and use of ketamine in combination with propofol in these cases (13).

The findings of the present study regarding basic hemodynamic parameters, showed a comparable decrease in heart rate, systolic, mean and diastolic blood pressure in both groups after induction, which was due to the loss of sympathetic stimulation on induction (28). These results were similar to the results of other studies for the EM group, $(2,13,16,17)$ and was in contrary with the result of a study by Singh Bajwa et al. (29) for the propofol-ketamine group that reported minimal increase in SBP and DBP after induction, which slowly reduced to normal values due to antagonistic properties of propofol (decrease in blood pressure) and ketamine (increase in blood pressure). We also observed that all of these variables increased near baseline or above baseline in both groups one minute after intubation, which was probably due to hemodynamic response to laryngoscopy and intubation. These results were similar to the results of other studies $(2,13)$.

The main findings of the present study regarding hemodynamic effects of induction drugs, showed a decrease in Cardiac Index (CI) in both groups after induction that may have been caused by decrease in stroke volume, accompanied by a decrease in arterial pressure. We also observed that cardiac index increased above baseline in both groups one and three minutes after intubation. This increase in cardiac index in the PK group at one and 3 minutes after intubation was more prominent than in the Etomidate-Midazolam (EM) group, which was probably due to hemodynamic response to laryngoscopy, intubation and the cardiovascular stimulatory effect of ketamine in the PK group. These results were similar to the results of the Singh et al. (2) and were in contrary with results of the Pandey et al. (23) that compared hemodynamic effects of etomidate and propofol induction. They reported the reduction of all variables including cardiac index over the time interval in both groups that were more prominent in the propofol group. In our study be- cause of admixture of ketamine with propofol, the cardiac index increased after intubation, and this increase was more than the etomidate group.

In the present study, we observed a significant decrease in Systemic Vascular Resistance (SVR) at different time intervals in both groups. Results were consistent with the results of the study done by Pandey et al. (23) and Singh et al.(2). The severity of SVR reduction was similar in both groups at one minute after induction, which may be due to the hemodynamic properties of midazolam and ketamine added to etomidate and propofol, respectively. However, at five minutes after intubation there was a significant reduction in SVR of the PK group in comparison with the EM group. We think these findings were because of the antagonistic properties of propofol and ketamine and dominancy of propofol properties after five minutes. The combination of propofol and ketamine has been studied in outpatients or in patients undergoing minor non-cardiac surgery, by numerous authors (13-17, 29, 30). In most of these studies the addition of a low-dose of ketamine has been shown to attenuate the cardiovascular depressing effects of propofol (31). However, we did not find any investigation that compared EM and PK combination in low EF patients undergoing CABG.

In conclusion, the results of this study suggest that both etomidate-midazolam and propofol-ketamine combinations produce stable hemodynamics and satisfactory induction conditions in patients with left ventricular dysfunction undergoing coronary artery bypass graft surgery. These combinations provide rapid, pleasant and safe anesthesia with only a few side effects and minor hemodynamic fluctuations. There were no adverse hemodynamic changes from induction until the end of our investigation.

\subsection{Study Limitations}

In the present study, the sample size $(n=17)$ for the investigation of cardiac index and systemic vascular resistance of patients may have not been enough.

\section{Authors' Contributions}

Nahid Aghdaii contributed to the study concept and design, data collection and approved the manuscript. Mohsen Ziyaeifard contributed to critical revision the manuscript. Seyedeh Zahra Faritus contributed to the data collection. Rasoul Azarfarin contributed to the biostatistcal analysis and data interpretation.

\section{References}

1. Bovill JG. Intravenous anesthesia for the patient with left ventricular dysfunction. Semin Cardiothorac Vasc Anesth. 2006;10(1):43-8.

2. Singh R, Choudhury M, Kapoor PM, Kiran U. A randomized trial of anesthetic induction agents in patients with coronary artery disease and left ventricular dysfunction. Ann Card Anaesth. 2010;13(3):217-23.

3. Guzelmeric F, Erdogan, H. B. , Kocak, T. . Anesthesiologic approach to cardiac emergencies. Turk J of Thoracic Cardiovascular Surgery. 2007;15:82-9. 
4. Mitter N, Grogan K, Daniel N, Berkowitz DE. Pharmocology of anesthetic drugs. In: Kaplan JA, Reich DL, Savino JS editors. Kaplan's Cardiac Anesthesia. 6 ed. Philadelphia: Saunders Elsevier; 2011. pp. 193-243.

5. Haessler R, Madler C, Klasing S, Schwender D, Peter K. Propofol/ fentanyl versus etomidate/fentanyl for the induction of anesthesia in patients with aortic insufficiency and coronary artery disease. J Cardiothorac Vasc Anesth. 1992;6(2):173-80.

6. Zielmann S, Kazmaier S, Schnull S, Weyland A. [S-(+)-Ketamine and circulation]. Anaesthesist. 1997;46 Suppl 1:S43-6.

7. Gooding JM, Weng JT, Smith RA, Berninger GT, Kirby RR. Cardiovascular and pulmonary responses following etomidate induction of anesthesia in patients with demonstrated cardiac disease. Anesth Analg. 1979;58(1):40-1.

8. Massaut J, d'Hollander A, Barvais L, Dubois-Primo J. Haemodynamic effects of midazolam in the anaesthetized patient with coronary artery disease. Acta Anaesthesiol Scand. 1983; 27(4):299-302.

9. Reiz S, Balfors E, Friedman A, Haggmark S, Peter T. Effects of thiopentone on cardiac performance, coronary hemodynamics and myocardial oxygen consumption in chronic ischemic heart disease. Acta Anaesthesiol Scand.1981;25(2):103-10.

10. Stephan H, Sonntag H, Schenk HD, Kettler D, Khambatta HJ. Effects of propofol on cardiovascular dynamics, myocardial blood flow and myocardial metabolism in patients with coronary artery disease. BrJ Anaesth. 1986;58(9):969-75.

11. el-Beheiry H, Kim J, Milne B, Seegobin R. Prophylaxis against the systemic hypotension induced by propofol during rapidsequence intubation. Can J Anaesth. 1995;42(10):875-8.

12. Ebert TJ, Muzi M, Berens R, Goff D, Kampine JP. Sympathetic responses to induction of anesthesia in humans with propofol or etomidate. Anesthesiology. 1992;76(5):725-33.

13. Basagan-Mogol E, Goren S, Korfali G, Turker G, Kaya FN. Induction of anesthesia in coronary artery bypass graft surgery: the hemodynamic and analgesic effects of ketamine. Clinics (Sao Paulo). 2010;65(2):133-8.

14. Andolfatto $\mathrm{G}$, Willman E. A prospective case series of pediatric procedural sedation and analgesia in the emergency department using single-syringe ketamine-propofol combination (ketofol). Acad Emerg Med. 2010;17(2):194-201.

15. Da-Silva PS, de Aguiar VE, Waisberg DR, Passos RM, Park MV. Use of ketofol for procedural sedation and analgesia in children with hematological diseases. Pediatr Int. 2011;53(1):62-7.

16. Phillips W, Anderson A, Rosengreen M, Johnson J, Halpin J. Propofol versus propofol/ketamine for brief painful procedures in the emergency department: clinical and bispectral index scale comparison. J Pain Palliat Care Pharmacother. 2010;24(4):349-55.

17. Wang M, Wang Q, Yu YY, Wang WS. An effective dose of ketamine for eliminating pain during injection of propofol: a dose response study. Ann Fr Anesth Reanim. 2013;32(9):e103-6.
18. Criado A, Maseda J, Navarro E, Escarpa A, Avello F. Induction of anaesthesia with etomidate: haemodynamic study of 36 patients. BrJAnaesth.1980;52(8):803-6.

19. Schwarzkopf KR, Hueter L, Simon M, Fritz HG. Midazolam pretreatment reduces etomidate-induced myoclonic movements. Anaesth Intensive Care. 2003;31(1):18-20.

20. Huter L, Schreiber T, Gugel M, Schwarzkopf K. Low-dose intravenous midazolam reduces etomidate-induced myoclonus: a prospective, randomized study in patients undergoing elective cardioversion. Anesthesia \& Analgesia. 2007;105(5):1298-302.

21. Isitemiz I, Uzman S, Toptas M, Vahapoglu A, Gul YG, Inal FY, et al. Prevention of etomidate-induced myoclonus: which is superior: Fentanyl, midazolam, or a combination? A Retrospective comparative study. Med Sci Monit. 2014;20:262-7.

22. Luan HF, Zhao ZB, Feng JY, Cui JZ, Zhang XB, Zhu P, et al. Prevention of etomidate-induced myoclonus during anesthetic induction by pretreatment with dexmedetomidine. Braz J Med Biol Res. 2015;48(2):186-90.

23. Pandey AK, Makhija N, Chauhan S, Das S, Kiran U, Bisoi AK, et al. The Effects of Etomidate and Propofol Induction on Hemodynamic and Endocrine Response in Patients Undergoing Coronary Artery Bypass Graft Surgery on Cardiopulmonary Bypass. World Journal of Cardiovascular Surgery. 2012;02(03):48-52.

24. Kosarek L, Hart SR, Schultz L, Digiovanni N. Increase in venous complications associated with etomidate use during a propofol shortage: an example of clinically important adverse effects related to drug substitution. Ochsner J. 2011;11(2):143-6.

25. Ayuso MA, Luis M, Sala X, Fernandez J, Gomar C. [Incidence of pain upon injection of a new formula of propofol in a fat emulsion of medium- and long-chain triglycerides]. Rev Esp Anestesiol Reanim. 2004;51(9):531-6.

26. Nyman Y, Von Hofsten K, Palm C, Eksborg S, Lonnqvist PA. Etomidate-Lipuro is associated with considerably less injection pain in children compared with propofol with added lidocaine. $\mathrm{Br} J$ Anaesth. 2006;97(4):536-9.

27. Habre C, Tramer MR, Popping DM, Elia N. Ability of a meta-analysis to prevent redundant research: systematic review of studies on pain from propofol injection. BMJ. 2014;348:g5219.

28. Neukirchen M, Kienbaum P. Sympathetic nervous system: evaluation and importance for clinical general anesthesia. Anesthesiology. 2008;109(6):1113-31

29. Singh Bajwa SJ, Bajwa SK, Kaur J. Comparison of two drug combinations in total intravenous anesthesia: Propofol-ketamine and propofol-fentanyl. Saudi J Anaesth. 2010;4(2):72-9.

30. Morse Z, Sano K, Kanri T. Effects of a midazolam-ketamine admixture in human volunteers. Anesth Prog. 2004;51(3):76-9.

31. Kamalipour H, Joghataie P, Kamali K. Comparing the Combination Effect of Propofol-Ketamine and Propofol-Alfentanil on Hemodynamic Stability during Induction of General Anesthesia in the Elderly. IRCMJ. 2009;11:176-80. 